\title{
Combined Effects of Corticosteroid, Thyroid Hormones, and $\beta$-Agonist on Surfactant, Pulmonary Mechanics, and $\beta$-Receptor Binding in Fetal Lamb Lung
}

\author{
DAVID WARBURTON, LANCE PARTON, SUE BUCKLEY, LINA COSICO, GREG ENNS, AND \\ TERRY SALUNA \\ Developmental Lung Biology Research Center, Division of Neonatology and Pediatric Pulmonology, Childrens \\ Hospital of Los Angeles, Los Angeles, California 90027
}

\begin{abstract}
We studied the interactions of corticosteroids, thyroid hormones, and $\beta$-agonist on surfactant phospholipids, pulmonary mechanics, and $\beta$-receptor binding in fetal lambs. We infused cortisol $(450 \mu \mathrm{g} / \mathrm{h}$ for $48 \mathrm{~h})$, thyrotropin-releasing hormone (TRH) $(25 \mu \mathrm{g} / \mathrm{h}$ for $48 \mathrm{~h})$, and ritodrine $(1.3 \mu \mathrm{g} / \mathrm{kg} / \mathrm{min}$ for $24 \mathrm{~h})$ independently, and in double (cortisol plus $\beta$-agonist, cortisol plus TRH), and in triple (cortisol plus TRH plus $\beta$-agonist) combinations into chronically catheterized fetal lambs between 0.88 and 0.90 gestation. Infusion of the triple combination of cortisol plus TRH plus $\beta$-agonist resulted in a 20.9 -fold increase in the saturated phosphatidylcholine content of fetal lung lavage, in a 5.8-fold increase in the saturated phosphatidylcholine content of whole fetal lung, and in a 13.3-fold increase in the saturated phosphatidylcholine content of fetal tracheal fluid. In addition, lung stability to inflation increased 3-fold, and lung stability to deflation increased 8 -fold. The increases in the saturated phosphatidylcholine content of fetal lung lavage and tracheal fluid were greater than the effects of each hormone acting independently, or in the double combinations. The $\beta$-receptor maximal binding capacity was increased $30 \%$ by the combined infusion of cortisol and TRH. In addition, the maximal binding capacity after cortisol plus TRH plus $\beta$-agonist infusion was $54 \%$ greater than the maximal binding capacity after $\beta$-agonist infusion. We conclude that the triple combination of cortisol, TRH, and $\beta$-agonist increases fetal lamb lung surfactant phospholipids better than do any of the hormones acting either independently, or in double combinations, and also improves pulmonary mechanics better than single hormones or the double combination of TRH and cortisol $(p<0.01)$. We speculate that the interaction of cortisol and TRH enhances the capacity of the fetal lamb lung to respond to $\beta$-adrenergic stimulation, and that the triple combination of cortisol plus TRH plus $\beta$-agonist might prepare the fetal lung for air breathing more effectively than each of the hormones acting either independently, or in the double combinations. (Pediatr Res 24: 166170, 1988)
\end{abstract}

Received January 4, 1988; accepted March 18, 1988.

Correspondence David Warburton, B.Sc., M.B., M.R.C.P., Division of Neonatology and Pediatric Pulmonology, Childrens Hospital of Los Angeles, 4650 Sunset Boulevard, Los Angeles, CA 90027.

Supported in part by NIH Special Emphasis Research Career Award 5K01 AM01130 and by the American Lung Association of Los Angeles County. L. P. was a research fellow of the Children's Hospital of Los Angeles Medical Group.

\author{
Abbreviations \\ Bmax, maximal binding capacity \\ DHA, dihydroalprenolol \\ $K$, dissociation constant \\ RDS, respiratory distress syndrome \\ SPC, saturated phosphatidylcholine \\ TRH, thyrotropin-releasing hormone \\ $V 40$, lung volume at $40 \mathrm{~cm}$ water air inflation pressure \\ $V 10$, lung volume at $10 \mathrm{~cm}$ water air deflation pressure \\ $T_{4}$, thyroxine \\ $\mathbf{T}_{3}$, tri-iodothyronine \\ TTI, free thyroxine index \\ PG, phosphatidylglycerol
}

Since Liggins (1) first described glucocorticoid effects on fetal lamb lung in 1969, evidence has accumulated that the fetal lung is also responsive to other hormones, including thyroid hormones and $\beta$-agonists (2). Glucocorticoids and thyroid hormones act at different points in the pathways of surfactant phospholipid synthesis (2), whereas $\beta$-agonists stimulate surfactant release and also regulate the production of fetal lung liquid (3). The maximal binding capacity of fetal lung $\beta$-receptors is regulated by glucocorticoids (4) and thyroid hormones (5).

Prenatal therapy with glucocorticoids reduces the incidence and severity of RDS, but is not always effective, especially in Caucasian male infants, in twins and after a short duration of therapy (6). Prenatal exposure to $\beta$-agonist has also been reported by Boog et al. (7) to decrease the incidence of RDS among premature infants. Recently Kwong and Egan (8) have reported that a combination of prenatal $\beta$-agonist and glucocorticoid therapy may be more effective than glucocorticoids alone in preventing RDS. Data from experimental systems suggest that thyroid hormones and glucocorticoids may also prove to be more effective in preventing RDS than glucocorticoids alone (2). Ikegami et al. (9) have recently reported that the combination of glucocorticoids and thyroid hormones improves the response of premature rabbit lungs to treatment with exogenous surfactants.

We used the chronically catheterized fetal lamb to test the hypothesis that cortisol, TRH, and $\beta$-agonists have combined effects on the availability of surfactant in fetal airways, and on fetal lung stability to air inflation and deflation. In addition, we studied the combined effects of these hormones on the binding characteristics of $\beta$-receptors in fetal lamb lung. 


\section{METHODS}

Western mixed-breed ewes pregnant with twins at a known gestational age from the time of mating were obtained from Nebeker Scientific, Lancaster, CA. Ossificiation centers in utero (10) and crown-rump measurements at delivery (11) were used to confirm the postconceptional ages provided by the supplier: they agreed within 3 days.

Nineteen ewes were operated on between 123 and 127 days gestation (term is 148 days in the sheep) under epidural anesthesia with $0.5 \%$ pontocaine as described previously (12). Catheters were placed in a fetal carotid artery, jugular vein, and the trachea. The $1.5-\mathrm{mm}$ internal diameter tracheal catheter was connected to a $600-\mathrm{ml}$ latex bag which was left in the uterus. A separate exit catheter from the bag was exteriorized through the ewe's flank together with the fetal artery and vein catheters. After the operation, the mothers received 1.2 million $\mathrm{U}$ of procaine penicillin and $10 \mathrm{mg}$ kanamycin, and were allowed to recover from the operation for 7 days.

The fetuses were assigned randomly to be controls (6) or to receive cortisol infusion (5), TRH infusion (4), $\beta$-agonist infusion (6), cortisol plus $\beta$-agonist infusion (6), cortisol plus TRH infusion (4), or cortisol plus TRH plus $\beta$-agonist infusion (5).

Cortisol was infused intravenously at a rate of $450 \mu \mathrm{g} / \mathrm{h}$ for 48 $\mathrm{h}$. This rate of cortisol was chosen because it produces elevation of serum cortisol level (13) similar to those reported by Mescher et al. (14) in fetal lambs near term. TRH was infused intravenously at a rate of $25 \mu \mathrm{g} / \mathrm{h}$ for $48 \mathrm{~h}$. This rate of TRH infusion was chosen because it produces significant stimulation of thyroid hormone production in fetal lambs (15). The preferential $\beta_{2^{-}}$ agonist Ritodrine was infused intravenously at a rate of $1.3 \pm$ $0.3 \mu \mathrm{g} / \mathrm{kg} / \mathrm{min}$ (mean $\pm \mathrm{SD}$ ) for $24 \mathrm{~h}$. This rate of Ritodrine infusion was chosen because it produces significant effects on tracheal fluid flow, surfactant, and pulmonary mechanics in fetal lambs (3). The hormones were given in $0.9 \%$ saline solution as a vehicle at a rate of $4 \mathrm{ml} / \mathrm{h}$. The controls received the saline infusion only.

A total of $3.5 \mathrm{ml}$ of arterial blood ( $1 \%$ of fetal blood volume) was taken from the fetuses on the day before the start of the hormone infusions, on the day before death, and on the day of death. Arterial blood gases were measured at $39^{\circ} \mathrm{C}$ with a Corning blood gas analyzer (Corning Instruments, Corning, NY) Serum cortisol, $\mathrm{T}_{4}, \mathrm{~T}_{3} \%$ uptake and FTI were measured by radioimmunoassay (Clinical Assays, Dade, Cambridge, MA).

Tracheal fluid was collected daily and stored at $-20^{\circ} \mathrm{C}$ for subsequent analysis. The animals were killed between 130 and 134 days $(0.88$ to 0.90$)$ gestation at the end of the hormone infusions with a rapid intravenous injection of sodium pentobarbital to the ewe and fetuses. The fetuses were immediately delivered from the uterus and the lungs were rapidly removed from the fetal thorax with clamping of the trachea to prevent egress of fetal lung fluid. The right upper lobe was cut into small pieces, rapidly frozen in liquid nitrogen, and stored at $-70^{\circ} \mathrm{C}$ for subsequent analysis. The biochemical analyses reported below were stable for several months using this method of tissue preservation. The left lung was used to record air pressure-volume curves using a method similar to that of Gribetz et al. (16). The V40 and the V10 were recorded. The left lung was then lavaged six or more times with a volume of saline equal to the V40 until a lavage volume of $280 \mathrm{ml}$ had been collected. The proportion of the lavage volume recovered was $\geq 65 \%$.

Lipids were extracted from the lung lavage, tracheal fluid, and from whole lung (17), and the SPC content was measured with osmic acid (18). The efficiency of the extraction of SPC was $\geq 91 \%$, measured by recovery of a trace amount of ${ }^{14} \mathrm{C}-\mathrm{SPC}$ added before the extraction. The lipid extracts were also analyzed by thin-layer chromatography using the method of Touchstone et al. (19). Lipids were expressed as $\mathrm{mg} / \mathrm{g}$ wet weight of lung.

The wet to dry weight ratio of the lungs was assessed by heating weighed pieces of lung to dryness in an $80^{\circ} \mathrm{C}$ oven. The protein content of the lungs was determined by the method of Markwell et al. (20) and the DNA content was determined by the method of Erwin et al. (21).

Beta-receptor binding assays for pulmonary membrane preparations were adapted from the methods described by Maniscalco and Shapiro (22). Fetal pulmonary membranes were prepared and the $\beta$-receptor assays were performed using $\left[{ }^{3} \mathrm{H}\right]$-DHA (New England Nuclear, Boston, MA) exactly as described previously by Warburton et al. (23).

Four term fetal lambs (145 days, 0.99 gestation) and four newborn lambs were also killed with intravenous pentobarbital and the lungs were removed and processed as above for comparison with the premature fetal lambs.

The data are expressed as the mean $\pm \mathrm{SD}$. Analysis of variance with the Newman-Kuel test was used to compare all the groups of lambs. Paired $t$ test was used to assess the effects of cortisol and TRH infusions on serum cortisol and thyroid hormone levels both within fetuses and between treated fetuses and controls. Statistical significance was accepted with a $p<0.05$.

\section{RESULTS}

The fetuses were killed between 130 and 134 days $(0.88$ to $0.90)$ gestation.

Fetal blood gases and hematocrit. Arterial blood gases in all the fetuses on the day before the hormone infusions were $\mathrm{pH}$ $7.38 \pm 0.01$ (mean $\pm \mathrm{SD}$ ), $\mathrm{PO}_{2} 23.5 \pm 0.3$ torr, and $\mathrm{PCO}_{2} 40.0$ \pm 0.4 torr. The arterial blood gases were not significantly different during the hormone infusions, except in the fetuses receiving $\beta$ agonist infusion with or without other hormones, in which the arterial blood pH $7.34 \pm 0.01$ and $\mathrm{PO}_{2} 20.5 \pm 0.6$ torr, were slightly lower, $p<0.01$, whereas $\mathrm{PCO}_{2} 41.1 \pm 0.3$ torr remained unchanged. The hematocrit of all fetuses before hormone infusion was $39 \pm 1 \%$ and did not change significantly during the experiment.

Fetal serum cortisol, $T_{4}, T_{3} \%$ uptake, and free thyroxine index. Cortisol infusion to the fetuses at a rate of $450 \mu \mathrm{g} / \mathrm{h}$ resulted in an increase in serum cortisol level from 2 to $4.2 \pm 0.2 \mathrm{mg} / \mathrm{dl}, p$ $<0.01$. Cortisol infusion in combination with TRH and/or $\beta$ agonist resulted in a similar elevation of fetal serum cortisol level.

TRH infusion to the fetuses at a rate of $25 \mu \mathrm{g} / \mathrm{h}$ resulted in a 1.5-fold increase in fetal serum $\mathrm{T}_{4}$ level from $8.4 \pm 1.7$ to 13.0 $\pm 4.6 \mu \mathrm{g} / \mathrm{ml}, p<0.05$, a 1.2 -fold increase in serum $\mathrm{T}_{3} \%$ uptake from $46.2 \pm 2.9$ to $57.6 \pm 5.5 \%, p<0.01$, and a 1.9 -fold increase in FTI from $10.9 \pm 2.2$ to $20.5 \pm 6.5, p<0.01$.

Lung protein, DNA, and wet/dry weight. The protein content of the control fetal lungs was $32 \pm 6 \mathrm{mg} / \mathrm{g}$ wet weight, the DNA content was $2.7 \pm 0.1 \mu \mathrm{g} / \mathrm{mg}$ wet weight, the dry weight was 4.4 $\pm 0.2 \mathrm{~g}$ and the wet/dry weight ratio was $0.107 \pm 0.006$ (dry weight $10.7 \pm 0.6 \%$ of wet weight). Lung protein content, DNA, lung weight, and wet/dry weight were not altered by the infusion of cortisol, TRH, or $\beta$-agonist either independently, or in the double or triple combinations.

The effects of the hormone infusions on tracheal fluid SPC content and SPC flux, on the SPC content of whole fetal lung, on the SPC and PG content of fetal lung lavage and on pulmonary mechanics are shown in Table 1.

SPC content of tracheal fluid. The triple combination of TRH plus cortisol plus $\beta$-agonist infusion resulted in a 14.0 -fold increase in the SPC content of tracheal fluid, $p<0.001$. This was a supraadditive increase with respect to the effects of each hormone acting alone, each of which resulted in a 2.2- to 3.7-fold increase in tracheal fluid SPC content, $p<0.05$. The double combinations of cortisol plus $\beta$-agonist and TRH plus cortisol resulted in 4.7- and 4.3-fold increases in tracheal fluid SPC content, respectively, $p<0.01$. Tracheal fluid SPC content of the fetuses treated with all three hormones was similar to that seen in the term fetuses. 
Table 1. Comparison of fetal lamb tracheal fluid SPC content, SPC flux, whole lung SPC content, lung lavage SPC, and PG content, and pulmonary mechanics (V40 and V10)*

\begin{tabular}{|c|c|c|c|c|c|c|c|c|}
\hline \multirow[b]{4}{*}{ Control } & \multirow[b]{3}{*}{$n$} & \multirow{3}{*}{$\begin{array}{c}\text { Tracheal } \\
\text { SPC } \\
\text { content } \\
(\mathrm{mg} / \mathrm{mI}) \\
\end{array}$} & \multirow{3}{*}{$\begin{array}{c}\text { Fluid } \\
\text { SPC } \\
\text { flux } \\
(\mathrm{mg} / \mathrm{kg} / \mathrm{h}) \\
\end{array}$} & \multirow{3}{*}{$\begin{array}{l}\text { Whole lung } \\
\text { SPC content } \\
\text { (mg/g wet wt) }\end{array}$} & \multicolumn{2}{|c|}{$\begin{array}{c}\text { Lung lavage } \\
\text { phospholipid content }\end{array}$} & \multirow{3}{*}{\multicolumn{2}{|c|}{$\begin{array}{l}\text { V40 V10 } \\
\text { (ml/g wet wt) }\end{array}$}} \\
\hline & & & & & SPC & PG & & \\
\hline & & & & & \multicolumn{2}{|c|}{ (mg/g wet wt) } & & \\
\hline & 6 & $12 \pm 1$ & $20 \pm 2$ & $1.2 \pm 0.1$ & $0.14 \pm 0.09$ & 0 & $0.4 \pm 0.1$ & $0.1 \pm 0.1$ \\
\hline Cortisol & 5 & $26 \pm 1 \dagger$ & $49 \pm 4 \ddagger$ & $2.1 \pm 0.2 \dagger$ & $0.43 \pm 0.11 \ddagger$ & $0.12 \pm 0.08 \dagger$ & $0.7 \pm 0.1 \dagger$ & $\begin{array}{c}0.4 \pm \\
0.1 \dagger\end{array}$ \\
\hline TRH & 4 & $31 \pm 2 \dagger$ & $59 \pm 14+$ & $2.3 \pm 0.2 \dagger$ & $0.57 \pm 0.23 \ddagger$ & $0.10 \pm 0.08 \dagger$ & $0.6 \pm 0.1 \dagger$ & $0.2 \pm 0.1$ \\
\hline Ritodrine & 6 & $44 \pm 7 \dagger$ & $<2$ & $2.9 \pm 0.2 \dagger$ & $0.72 \pm 0.17 \ddagger$ & $0.02 \pm 0.07 \dagger$ & $0.7 \pm 0.1 \dagger$ & $\begin{array}{r}0.5 \pm \\
0.1 \dagger\end{array}$ \\
\hline Cortisol and ritodrine & 6 & $56 \pm 9 \$$ & $<2$ & $3.9 \pm 0.2 \ddagger$ & $1.03 \pm 0.23 \neq$ & $0.20 \pm 0.06 \ddagger$ & $1.0 \pm 0.1 \ddagger$ & $\begin{array}{l}0.7 \pm \\
0.1 \pm\end{array}$ \\
\hline TRH and cortisol & 4 & $51 \pm 12 \ddagger$ & $89 \pm 20 \ddagger$ & $3.5 \pm 0.3 \ddagger$ & $0.79 \pm 0.09 \$$ & $0.13 \pm 0.06 \dagger$ & $0.8 \pm 0.1 \dagger$ & $\begin{array}{c}0.5 \pm \\
0.1 \dagger\end{array}$ \\
\hline $\begin{array}{l}\mathrm{TRH} \text { and cortisol and } \\
\text { ritodrine }\end{array}$ & 5 & $160 \pm 25 \xi \cdot \|$ & $<2$ & $5.0 \pm 0.6 \S \boldsymbol{\pi}$ & $1.90 \pm 0.27 \S^{* * *}$ & $0.45 \pm 0.09 \S^{, * *}$ & $1.2 \pm 0.2 \ddagger \|$ & $\begin{array}{l}0.8 \pm \\
0.1 \neq \|\end{array}$ \\
\hline Term fetuses & 4 & $168 \pm 41 \S$ & $171 \pm 42 \S$ & $5.6 \pm 0.5 \S$ & $1.51 \pm 0.30 \S$ & $0.50 \pm 0.08 \S$ & $0.9 \pm 0.2 \dagger$ & $\begin{array}{c}0.7 \pm \\
0.1 \neq\end{array}$ \\
\hline Newborn lambs & 4 & & & $6.1 \pm 0.7 \S$ & $2.53 \pm 0.14 \S$ & $0.81 \pm 0.09 \S$ & $1.8 \pm 0.2 \S$ & $\begin{array}{r}1.2 \pm \\
0.2 \S\end{array}$ \\
\hline
\end{tabular}

* Mean \pm SD are shown for control fetuses, for fetuses treated with $\beta$-agonist (ritodrine), cortisol, or TRH infusion, either independently or in double (cortisol plus ritodrine, TRH plus cortisol) or triple combinations (TRH plus cortisol plus ritodrine), for term fetuses and for newborn lambs.

$\dagger p<0.05$ in comparison with control.

$\$ p<0.01$ in comparison with control.

$\S p<0.001$ in comparison with control.

$\| p<0.01$ in comparison with the TRH and cortisol group.

$\mathbb{\pi} p<0.01$ in comparison with both double hormone groups.

${ }^{* *} p<0.001$ in comparison with both double hormone groups.

Tracheal fluid flow. Tracheal fluid flow in the control lambs was $3.2 \pm 0.4 \mathrm{ml} / \mathrm{kg} / \mathrm{h}$ and did not change with hormone infusion, except in fetuses receiving $\beta$-agonist, either singly, or in combination with other hormones, in which tracheal fluid flow fell to $0.1 \mathrm{ml} / \mathrm{kg} / \mathrm{h}$.

SPC flux into tracheal fluid. Tracheal fluid SPC flux was increased 2.5 -fold by cortisol, 3.0-fold by TRH, and 4.5 -fold by TRH plus cortisol, $p<0.01$. However, in fetuses receiving $\beta$ agonist infusion, either singly or in combination with the other hormones, tracheal fluid SPC flux was almost completely inhibited by the marked reduction of tracheal fluid flow.

$S P C$ content of whole lung. The triple combination of cortisol plus TRH plus $\beta$-agonist infusion resulted in a 5.8 -fold increase in the SPC content of whole fetal lamb lung in comparison with controls, $p<0.001$. This was an approximately additive increase with respect to the effects of each hormone acting alone, each of which resulted in a 1.8- to 2.4-fold increase in whole fetal lung SPC content, $p<0.05$. The double combinations of cortisol plus $\beta$-agonist and cortisol plus TRH also resulted in 3.2- and 2.9fold increases in whole lung SPC content, $p<0.01$. The pulmonary SPC content of the fetuses infused with all three hormones was similar to that found in the term fetuses and in the newborn lambs.

$S P C$ and $P G$ content of lung lavage. The triple combination of cortisol plus TRH plus $\beta$-agonist also resulted in a 20.9 -fold increase in the SPC content of fetal lung lavage, $p<0.001$. This effect was supraadditive with respect to the effects of each hormone acting singly or in double combinations. The single hormones increased the SPC content of fetal lung lavage significantly (cortisol by 3.1 -fold, TRH by 4.1 -fold, $\beta$-agonist by 5.4 -fold, $p<$ 0.01 ). The effects of the double combinations of hormones on the SPC content of fetal lung lavage were slightly less than additive (cortisol plus $\beta$-agonist 7.4-fold, cortisol plus TRH 5.7fold, $p<0.01$ ). The lung lavage SPC content of the fetuses infused with all three hormones was comparable to that found in term fetuses, but was $36 \%$ lower than that found in newborn lambs, $p<0.01$.

PG could not be detected in the lung lavage from control fetuses. Low amounts of PG could be detected in lung lavage from the fetuses treated with either single hormones or the double combinations of hormones. Triple hormone infusion resulted in amounts of PG in premature fetal lung lavage similar to those seen in the term fetuses, but $38 \%$ less than in newborn lambs, $p$ $<0.05$.

Pulmonary mechanics. The triple combination of cortisol plus TRH plus $\beta$-agonist resulted in a 3.0 -fold increase in V40 and an 8.0 -fold increase in $\mathrm{V} 10, p<0.01$. This combined effect was greater than that of either the single hormones, or the double combination of TRH and cortisol, $p<0.01$. However, the single hormones also increased V40 (cortisol by 1.8 -fold, TRH by $1.5-$ fold, $\beta$-agonist by 1.8 -fold, $p<0.05$ ) and V10 (cortisol by 4.0 fold, $\beta$-agonist by 5.0-fold, $p<0.01$, but not TRH). In addition, cortisol plus $\beta$-agonist produced a 2.5 -fold increase in V40 and a 7.0-fold increase in V10, $p<0.01$, whereas TRH plus cortisol produced a 2.0 -fold increase V40 and a 5.0-fold increase in V10, $p<0.05$.

Beta-receptor binding. Specific $\left[{ }^{3} \mathrm{H}\right] \mathrm{DHA}$ binding to fetal lung membranes was saturable, and Scatchard analysis was linear, indicating a predominance of one class of binding sites. The binding was also stereospecific, inasmuch as the concentration of the $d$-stereoisosmer of isoproterenol required to give halfmaximal inhibition of binding was 100-fold higher than that of the l-stereoisomer. Competitive binding studies indicated that the order of potency of $\beta$-agonists as competitors for $1-\left[{ }^{3} \mathrm{H}\right]-\mathrm{DHA}$ was l-isoproterenol $>$ l-epinephrine $>$ l-norepinephrine. These results were the same as we have reported previously in fetal lamb lung (23).

The effects of the hormone infusions on the fetal pulmonary Bmax are shown in Figure 1. Infusion with $\beta$-agonist resulted in a decreased $\beta$-receptor Bmax in both control $(-57 \%)$ and corti- 


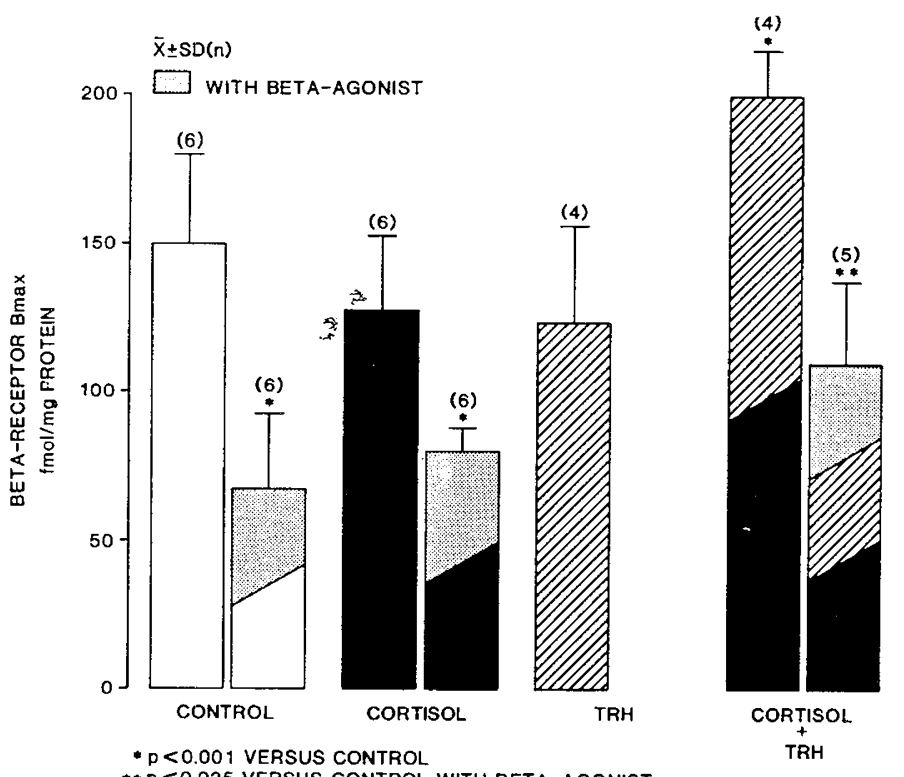

Fig. 1. Comparison of $\beta$-receptor Bmax in fetal lamb lung membranes using DHA as ligand.

sol-infused fetuses $(-38 \%)$. In contrast, the combination of cortisol and TRH infusion resulted in a $30 \%$ increase in Bmax, to $190 \pm 12 \mathrm{fmol} / \mathrm{mg}$ protein, a level similar to the Bmax in term fetuses $(185 \pm 14 \mathrm{fmol} / \mathrm{mg}$ protein) and newborn lambs $(188 \pm$ $5 \mathrm{fmol} / \mathrm{mg}$ protein).

In comparison to the Bmax in cortisol plus TRH-infused fetuses, $\beta$-agonist infusion to fetuses previously treated with cortisol plus TRH decreased the Bmax by $50 \%$. However, the Bmax was then $54 \%$ more than in fetuses receiving only $\beta$ agonist infusion. The $K$ in the control fetuses was $3.4 \pm 0.6 \mathrm{mM}$ and was not affected by hormone infusion.

\section{DISCUSSION}

The lung SPC content, lung lavage and tracheal fluid SPC and PG content, the V40 and the V10 in control fetuses are consistent with previously published reports of normal values for fetal lambs (24). Lung protein, DNA, and wet/dry weight ratio were also normal in controls, and were unchanged by the hormone treatments. The presence of the small $(1.5 \mathrm{~mm})$ bore tracheal catheter in this and previous experiments (23) did not affect lung growth, as reflected by lung wet weight, protein and DNA content, and dry weight.

Gestational age of the fetuses was carefully controlled in this study inasmuch as the period between 0.88 and 0.90 gestation is one of increasing maturity in controls. However, the hormonal effects we measured were significantly greater than the effects of normal fetal lung development between 0.88 and 0.90 gestation. In addition, the hormone infusions were given in random order to minimize possible seasonal or selection biases.

The numbers of fetuses in each group were too small to detect or exclude an effect of fetal gender on the response to hormone infusion. However, this may be important because male human infants do not always respond to glucocorticoid therapy (6), and there is a female advantage in $\beta$-receptor maturation and surfactant development in fetal lambs (23).

Infusion of cortisol resulted in elevation of fetal serum cortisol to levels similar to those reported previously from our laboratory (13). These levels were similar to those reported to occur spontaneously by Mescher et al. (14) in catheterized control fetuses near term. The TRH infusion resulted in elevation of fetal serum thyroid hormone levels similar to those reported by Thomas et al. (15) after TRH infusion. The effects of $\beta$-agonist infusion on fetal arterial blood gases were also similar to those which we reported previously (3). Fetal arterial blood gases were otherwise normal and were unaffected by the hormone infusions.

The independent effects of cortisol and $\beta$-agonists on surfactant phospholipids in tracheal fluid and lung lavage of fetal lambs were consistent with those reported previously by ourselves and others $(3,13,25)$. We reported recently that the inhibitory effects of ritodrine on lung liquid production could only account for $18 \%$ of the increase in surfactant recoverable in lung lavage (3). Therefore a mere concentration effect could not explain the increase in lung lavage surfactant.

The SPC content of whole lung tissue does not distinguish specifically between surfactant-associated and membrane-associated pools of phospholipid, whereas postmortem lung lavage only provides an estimate of the alveolar surfactant pool in vivo. However, the flux of surfactant SPC into the tracheal fluid of chronically catheterized fetal lambs has been used by several groups of investigators as a marker of pulmonary surfactant production $(3,13,14,25)$. Taking the data on SPC content of whole lung and SPC and PG content of lung lavage together with the data on tracheal fluid content of SPC, we conclude that the triple combination of cortisol, TRH, and $\beta$-agonist enhances the availability of pulmonary surfactant phospholipid in the airways of the fetal lamb better than do any of the hormones acting either singly or in the double combinations.

Pulmonary mechanics measured as the stability of the lungs to inflation and deflation with air were also improved to a greater extent by the combination of cortisol plus TRH plus $\beta$-agonist than by single hormone infusions or by the double combination of cortisol plus TRH. The increases in V10 are consistent with an increase in alveolar surfactant. However, the concomitant increases in V40 suggest that distensibility of the airways and interstitium also improved. Thinning out of the pulmonary interstitium after glucocorticoid treatment was among the original morphological observations of Liggins (1). Improved surfactant availability in the airways with enhanced stability of the lung to inflation and deflation would be consistent with a decreased propensity to develop RDS in neonates.

We have recently shown that the onset of $\beta$-receptor maturation coincides with the appearance of surfactant in tracheal fluid in fetal lambs, and that the Bmax approximately doubles between 0.84 and 0.89 gestation (20). The changes in Bmax reported here in response to hormone infusion were significantly greater than those reported in control fetal lambs during the same period of gestation. In the rabbit fetus, glucocorticoids increase the number of $\beta$-receptor binding sites (4), whereas in the rat fetus hypothyroidism decreases the number of binding sites (5). The lack of effect of corticosteroids alone on $\beta$-receptor binding capacity in the fetal lamb lung may be due either to a species difference or to the physiological concentrations of cortisol used herein in comparison with the pharmacological concentrations used in other systems (2).

Ballard (2) has suggested that both thyroid hormones and corticosteroids act directly in type II pneumocytes to induce different sets of gene sequences coding for different proteins. Thus, there would be overall additive or synergistic effects on surfactant phospholipid biosynthesis resulting in additive or synergistic effects on surfactant production. We speculate that the combination of cortisol and TRH induces components of the $\beta$ adrenergic signal transduction system in fetal lamb lung so that the response to $\beta$-adrenergic stimulation is enhanced, in addition to any other possible effects on surfactant phospholipid synthesis.

We conclude that the triple combination of cortisol, TRH, and $\beta$-agonist increases fetal lamb lung surfactant phospholipids better than any of the hormones acting either independently, or in the double combinations we studied. Moreover, the triple combination of cortisol, TRH, and $\beta$-agonist improves fetal pulmonary mechanics better than any of the hormones acting independently, or the double combination of cortisol and TRH. We speculate that the triple combination of cortisol plus TRH plus $\beta$-agonist might prepare the fetal lung for air breathing more 
effectively than each of the hormones acting either independently or in double combinations.

Acknowledgments Ritodrine was a gift of Astra Pharmaceutical, Inc. Mary DiNallo provided secretarial assistance.

\section{REFERENCES}

1. Liggins GC 1969 Premature delivery of foetal lambs infused with glucocorticoids. J Endocrinol 45:515-519

2. Ballard PL 1986 Hormones and lung maturation. Monogr Endocrinol 28:197_ 346

3. Warburton D, Parton L, Buckley S, Cosico L, Saluna T 1987 Effects of beta-2 agonist on tracheal fluid, surfactant, and pulmonary mechanics in the fetal lamb. J Pharmacol Exp Ther 242:394-398

4. Cheng JB, Goldfien A, Ballard PL, Roberts JM 1980 Glucocorticoids increase pulmonary beta-adrenergic receptors in fetal rabbit. Endocrinology 107:1646-1648

5. Whitsett JA, Darovec-Beckerman C, Pollinger J, Moore JJ 1982 Ontogeny of beta-adrenergic receptors in the rat lung: effects of hypothyroidism. Pediatr Res 16:381-387

6. Collaborative Group on Antenatal Steroid Therapy 1981 Effect of antenatal dexamethasone adminstration on the prevention of respiratory distress syndrome. Am J Obstet Gynecol 82:285-288

7. Boog G, Brahim MB, Gaudar R 1975 Beta-mimetic drugs and possible prevention of respiratory distress syndrome. Br J Obstet Gynaecol 82:285-288

8. Kwong MS, Egan EA 1986 Reduced incidence of hyaline membrane disease in extremely premature infants following delay of delivery of mother with preterm labor: use of ritodrine and betamethasone. Pediatrics 78:767-774

9. Ikegami M, Jobe AH, Pettenazo A, Seidner SR, Berry DB, Ruffini L 1987 Effects of maternal treatment with corticosteroids. T3, TRH, and their combinations on lung function of ventilated preterm rabbits with and without surfactant treatments. Am Rev Respir Dis 136:892-898

10. Lascelles AK 1959 The time of appearance of ossification centers in the peppintype merino. Aust J Zool 7:79-86

11. Barcroft J 1947 Researches on Pre-natal Life, Vol 1. Charles C Thomas,
Springfield, IL

12. Warburton D 1983 Chronic hyperglycemia inhibits surface active material flux in tracheal fluid of fetal lambs. J Clin Invest 71.550-555

13. Warburton D 1983 Chronic hyperglycemia inhibits the response of fetal lamb lungs to cortisol. J Clin Invest 72:433-440

14. Mescher EJ, Platzker ACG, Ballard PL, Kitterman JA, Clements JA, Tooley WH 1975 Ontogeny of tracheal fluid, surfactant and plasma corticoids in the fetal lamb. J Appl Physiol 39:1017-1021

15. Thomas AL, Jack PMB, Manns JG, Nathanielsz PW 1975 Effect of synthetic thyrotropin releasing hormone on thyrotropin, prolactin, thyroxine, and triiodothyronine in the peripheral plasma of the pregnant ewe, lamb fetus, and neonatal lamb. Biol Neonat 26:109-116

16. Gribetz I, Frank NR, Avery ME 1959 Static pressure-volume relations of excised lungs of infants with hyaline membrane disease, newborn and stillborn infants. J Clin Invest 38:2168-2175

17. Bligh EG, Dyer WJ 1959 A rapid method of total lipid extraction and purification. Can J Biochem Physiol 37:911-917

18. Mason RJ, Nellenbogen J, Clements JA 1976 Isolation of desaturated phosphatidylcholine with osmium tetroxide. J Lipid Res 17:281-284

19. Touchstone JC, Levin SS, Dobbins MF, Beers PC 1981 Differentiation of saturated and unsaturated phospholipids on thin-layer chromatograms. J High Resolution Chromatog 4:423-424

20. Markwell MA, Haas SM, Bieber LL, Tolbert NE 1979 A modification of the Lowry procedure to simplify protein determinations in membrane and lipoprotein samples. Anal Biochem 87:206-210

21. Erwin BG, Stoschek CM, Florini JR 1981 A rapid fluorimetric method for the estimation of DNA in cultured cells. Anal Biochem 110:291-294

22. Maniscalco WM, Shapiro DL 1983 Effects of dexamethasone on beta-adrenergic receptors in fetal lung explants. Pediatr Res 17:274-277

23. Warburton D, Parton L, Buckley S, Cosico L, Saluna T 1987 Beta receptors and surface active material flux in fetal lamb lung; female advantage. $\mathrm{J}$ Appl Physiol 63:828-833

24. Kitterman JA, Liggins GC, Campos GA, Clements JA, Forster CS, Lee $\mathrm{CH}$ Creasy RK 1981 Prepartum maturation of the fetal lung in fetal sheep: relation to cortisol. J Appl Physiol 51:384-390

25. Platzker ACG, Kitterman JA, Mescher J, Clements JA, Tooley WH 1975 Surfactant in the lung and tracheal fluid of the fetal lamb and acceleration of its appearance by dexamethasone. Pediatrics 56:554-561 